\title{
The Protective Effect of Testosterone on the Ovarian Reserve During Cyclophosphamide Treatment
}

This article was published in the following Dove Press journal: OncoTargets and Therapy

\author{
Masae Yoo (D) \\ Tomohito Tanaka (D) ${ }^{1,2}$ \\ Hiromi Konishi $\mathbb{I D}^{\prime}$ \\ Akiko Tanabe' \\ Kohei Taniguchi $\mathbb{D}^{2}$ \\ Kazumasa Komura $\mathbb{D}^{2}$ \\ Masami Hayashi' \\ Masahide Ohmichi' \\ 'Department of Obstetrics and \\ Gynecology, ${ }^{2}$ Translational Research \\ Program, Osaka Medical College, \\ Takatsuki, Japan
}

Introduction: Cyclophosphamide, which is widely used to treat malignant disease, causes ovarian follicular atresia, which leads to premature ovarian insufficiency. The present study evaluated the protective effect of testosterone in preventing the decline in the ovarian reserve during cyclophosphamide treatment.

Methods: Using the COV434 human granulosa cell line, the protective effect of testosterone against cyclophosphamide was evaluated by immunocytochemistry, Western blotting and an MTS assay. The follicles in mouse ovaries and serum anti-Mullerian hormone were also assessed to evaluate the effects of testosterone.

Results: Testosterone suppressed the decrease in cell viability and apoptosis caused by cyclophosphamide treatment in vitro. In vivo, the number of atretic follicles in the mouse ovary was significantly lower in the testosterone plus cyclophosphamide group than in the cyclophosphamide alone group $(\mathrm{p}=0.03)$. The serum anti-Mullerian hormone was significantly higher in the testosterone plus cyclophosphamide group than in the cyclophosphamide alone group (16.2 [9.7-22.6]) vs 11.2 [8.9-12.1], $\mathrm{p}<0.01)$. The rate of cleaved Caspase-3 expression in the testosterone plus cyclophosphamide group was lower than that in the cyclophosphamide alone group (28.4\% vs $48.6 \%$, p=0.03).

Conclusion: These findings indicated that testosterone has the potential to prevent ovarian damage induced by cyclophosphamide by protecting granulosa cells from cyclophosphamide-induced apoptosis.

Keywords: cyclophosphamide, follicular atresia, granulosa cells, primary ovarian insufficiency, testosterone

\section{Introduction}

In recent decades, chemotherapy has improved the prognosis of patients with malignancies; however, there have been serious side effects, including ovarian failure or infertility. ${ }^{1,2}$ The serious side effects related to ovarian dysfunction include vasomotor symptoms, osteoporosis, increased risk of cardiovascular disease, sexual dysfunction and infertility, and therefore represent an important problem, especially in adolescent and young women. ${ }^{3}$ Protection against iatrogenic infertility and loss of the endocrine ovarian function caused by chemotherapy is currently considered a high priority. ${ }^{4}$ Cyclophosphamide, which is categorized as an alkylating drug, is commonly used as chemotherapeutic and immunosuppressive agent for the treatment of patients with malignancy or autoimmune disease. The American Society of Clinical Oncology (ASCO) guideline shows that treatment with cyclophosphamide
Correspondence: Tomohito Tanaka Department of Obstetrics and Gynecology, Osaka Medical College, 2-7, Daigaku-machi, Takatsuki, Osaka 569-8686, Japan

Email gynI23@osaka-med.ac.jp 
$>7.5 \mathrm{~g} / \mathrm{m}^{2}$ carries a risk of including further infertility in patients with pediatric cancer, ${ }^{5}$ and the Childhood Cancer Survivor Study (CCSS) support this, with findings showing that treatment with cyclophosphamide $>11.3 \mathrm{~g} / \mathrm{m}^{2}$ carries a risk of including infertility; ${ }^{6}$ cyclophosphamide treatment can also lead to impaired fertility or ovarian failure due to destruction of follicles. ${ }^{7-9}$ Previous studies have demonstrated follicular decline after cyclophosphamide treatment, and have indicated that apoptotic changes in granulosa and theca cells are the mechanism that leads to follicle loss. ${ }^{10}$

In previous reports, testosterone was shown to be essential for normal follicular development; it enhances follicular recruitment, ${ }^{11}$ promotes follicular growth and development, ${ }^{12}$ increases the insulin-like growth factor 1 expression in the primate ovary to induce follicular development, ${ }^{13}$ and increases follicular sensitivity to follicle-stimulating hormone via the androgen receptor. ${ }^{14,15}$ However, high concentrations of testosterone inhibit follicle development through the regulation of the folliclestimulating hormone signaling pathway. ${ }^{16}$ Gonadotropinreleasing hormone analogues, which inhibit the proliferation of granulosa cells and growth of follicles, resulting in the preservation of premature follicles in the ovary, have been administered to prevent chemotherapy-related amenorrhea in patients of reproductive age who are undergoing chemotherapy. Similar to the effects of gonadotropin-releasing hormone, high concentrations of testosterone induced follicle development arrest. We therefore hypothesized that testosterone has a potential therapeutic application in preventing the decline of the ovarian function in patients undergoing chemotherapy. The aim of this study was to evaluate the protective effect of testosterone in preventing the decline of the ovarian reserve during cyclophosphamide treatment.

\section{Materials and Methods}

\section{Reagents and Antibodies}

The rabbit monoclonal anti-human $\beta$-actin antibodies (4970, Cell Signaling Technology, Inc., Danvers, MA, USA) and the rabbit polyclonal anti-human BimEL antibodies (ab\#2819, Abcam, Cambridge, MA, USA) were used for immunoblotting. The rabbit polyclonal anti-human Cleave-caspase-3 antibody (Merck Millipore, Billerica, MA, USA) was used for immunoblotting and immunohistochemistry. The cyclophosphamide and testosterone used in the in vitro and in vivo experiments were purchased from Selleck Chemicals (Houston, TX, USA). Flutamide was purchased from Sigma-Aldrich (St. Louis, MO, USA). BD Falcon $^{\mathrm{TM}}$ 96-well microplates (BD, Franklin Lakes, NJ, USA) were used for the cell proliferation assays.

\section{Cell Lines and Conditioned Media}

We used the human granulosa cell line COV434 in this study. COV434 cells were obtained from the American Type Culture Collection (ATCC, Rockville, MD, USA) in 2015. The authentication was obtained by Human STR Profiling Cell Authentication Service, and mycoplasma test was tested in all cell lines. All of the experiments were performed at $<15-20$ passages.

COV434 cells were grown in Dulbecco's Modified Eagle's Medium supplemented with $10 \%$ charcoalstripped fetal bovine serum (Equitech-Bio, Kerrville, TX, USA) in an atmosphere of $5 \% \mathrm{CO}_{2}$ at $37^{\circ} \mathrm{C}$. Serum-free Dulbecco's Modified Eagle's Medium was used for cell starvation.

After 2-h starvation, the COV434 cells were treated with various concentrations of testosterone $(0,10,100 \mathrm{nM})$ with or without testosterone inhibitor flutamide and incubated for $6 \mathrm{~h}$. Subsequently, various concentrations of cyclophosphamide $(0,1,10,100,1000 \mu \mathrm{M})$ were added and incubated for $48 \mathrm{~h}$. The MTS assay, immunostaining, caspase-3 activity assay and Western blotting were then performed. COV434 cells treated with testosterone at concentrations exceeding $100 \mathrm{nM}$ had no proliferative activity. Previous study has shown that testosterone at a concentration of 10 $\mathrm{nM}$ is close to the physiological value. ${ }^{17}$ We therefore set the concentration of testosterone $10 \mathrm{nM}$.

\section{Western Blotting}

Pierce Radio-Immuno Precipitation Assay Buffer (Thermo Fisher Scientific, MA, USA) was used to prepare total proteins. Sodium dodecyl sulfate-polyacrylamide gel electrophoresis was performed to separate whole-cell proteins into equal amounts, which were then electro-transferred to nitrocellulose membranes. Non-specific antigen sites were blocked with $10 \%$ bovine serum albumin in $1 \times$ Trisbuffered saline for $1 \mathrm{~h}$. Western blotting was performed using the above-described specific primary antibodies. Immunoreactive bands in immunoblots were visualized with horseradish peroxidase-coupled goat anti-rabbit immunoglobulin by an ECL Plus (GE Healthcare Life Sciences, Pittsburgh, PA, USA), which is an enhanced chemiluminescence Western blotting system. All experiments were repeated at least three times and yielded similar results on each occasion. 


\section{Detection of Apoptotic Cells}

COV434 GC cell apoptosis under various conditions was assessed using a caspase activity assay with the CspACETM FITC-VAD-FMK In Situ Marker (Promega, WI, USA), according to the manufacturer's instructions. A confocal laser scanning microscope (Carl Zeiss Microscopy $\mathrm{GmbH}$, Gottingen, Germany) was used to analyze the slides, and flow cytometry was performed using a Fluorescenceactivated cell sorter system, to quantify the level of apoptosis according to the rate of testosterone depletion. For each sample, approximately 10,000-gated events were analyzed. The analysis of the results was performed with the Windows Multiple Document Interface for Flow Cytometry software program, and the rate of apoptosis was determined.

\section{The Enzyme-Linked Immunosorbent Assay (ELISA)}

Serum samples were collected from mice and immediately centrifuged. Sera were stored at $-20{ }^{\circ} \mathrm{C}$. An enzyme-linked immunosorbent assay with a human anti-Mullerian hormone immunoassay (Abcam, Cambridge, MA) was performed, in accordance with the manufacturer's instructions, to analyze the serum anti-Mullerian hormone levels. Absorbance was read at $450 \mathrm{~nm}$ with an absorbance microplate reader (Corona SH-1000Lab, Corona Electric Co. Inc, Ibaraki, Japan). The concentrations of the sample concentrations were determined by interpolation from the standard curve. Five independent experiments were performed. The results were expressed as the mean \pm standard deviation.

\section{H\&E Staining and Immunohistochemistry}

Tissue samples were fixed in formalin and embedded in paraffin. For antigen retrieval, deparaffinized and rehydrated sections (thickness: $4 \mu \mathrm{m}$ ) were autoclaved in $0.01 \mathrm{~mol} / \mathrm{L}$ citrate buffer ( $\mathrm{pH} 6.0$ ) for $15 \mathrm{~min}$ at $121^{\circ} \mathrm{C}$. Endogenous peroxidase activity was blocked using $0.3 \%$ hydrogen peroxide solution in methanol for $30 \mathrm{~min}$. The sections were then incubated at $4{ }^{\circ} \mathrm{C}$ for $12 \mathrm{~h}$ with an anti-cleaved caspase- 3 antibody at 1:800 dilution. Sections were subsequently washed with $1 \times$ phosphate-buffered saline, then incubated with Histofine Simple Stain MAX PO (multi; Nichirei) for 30 min at room temperature. The sections were then washed with $1 \times$ phosphate-buffered saline and visualized by incubating with $\mathrm{H}_{2} \mathrm{O}_{2}$ /diaminobenzidine substrate solution for 5 min. Finally, the sections were counterstained with hematoxylin before dehydration and mounting. The immunohistochemical data were analyzed by two independent pathologists who were blinded to the clinicopathological data. The largest six ovaries resected from five mice were evaluated; the numbers of follicles categorized into five conditions (primordial follicles, primary follicles, secondary follicles, corpus lutea and atretic follicles) were counted. The ratio of $\mathrm{Cl}$-caspase-3 positive cells was also counted.

\section{Animal Study}

The protocol of the present study was approved by the Animal Care and Use Committee of Osaka Medical College. All procedures were approved by the Osaka Medical College Animal Committee and were in accordance with the institutional guidelines for animal welfare and experimental conduct. Six-week-old female BALB/c mice (purchased from Japan SLC, Int.). Three mice were housed per cage. The mice had ad libitum access to sterile food pellets and water. Cyclophosphamide $(100 \mathrm{mg} / \mathrm{kg})$ was suspended in $1 \%$ saline (Sigma-Aldrich), and was injected into the abdominal cavity 3 times on days 1,4 and 7 . Testosterone $(4 \mathrm{mg} / \mathrm{kg}$ ) was suspended in corn oil at a concentration, and subcutaneously injected 4 times (days 1, 4, 7 and 10). PBS (1 mL) was injected in the abdominal cavity 3 times (days 1, 4 and 7) in the vehicle group. All animals were sacrificed on day 14 and the blood and ovaries were collected and snap-frozen or fixed. The serum anti-Mullerian hormone levels were measured with enzyme-linked immunosorbent assay (Figure 1). The dosage of cyclophosphamide was decided based on previously published literature. ${ }^{18-22}$ Furthermore, cyclophosphamide was injected three times because the aim of this study was to prevent serious dysfunction of the ovary. The dosage of testosterone was also decided based on previously published reports, ${ }^{23}$ and the serum testosterone level of mice that received testosterone $(4 \mathrm{mg} / \mathrm{kg})$ injection four times (days 1 , 4,7 and 10) was $1.04(0.51-1.11) \mathrm{ng} / \mathrm{mL}$. In previous studies, the serum testosterone level in control mice was $0.19 \mathrm{ng} / \mathrm{mL}$. In contrast, the serum testosterone level in mice with continuous-release pellets containing $10 \mathrm{mg}$ dihydrotestosterone was $1.64 \mathrm{ng} / \mathrm{mL}$, which considered a high concentration of testosterone. ${ }^{16}$ This is how we decided on the dosages of cyclophosphamide and testosterone for the present study.

\section{Statistical Analyses}

All statistical analyses were performed using the JMP software package (version. 14.1.1, SAS Institute Inc., Tokyo, Japan). Continuous variables are expressed as the median and interquartile range or mean \pm standard deviation. The results were compared using the Kruskal-Wallis test and Mann-Whitney $U$-test or paired $t$-test, as appropriate. When 


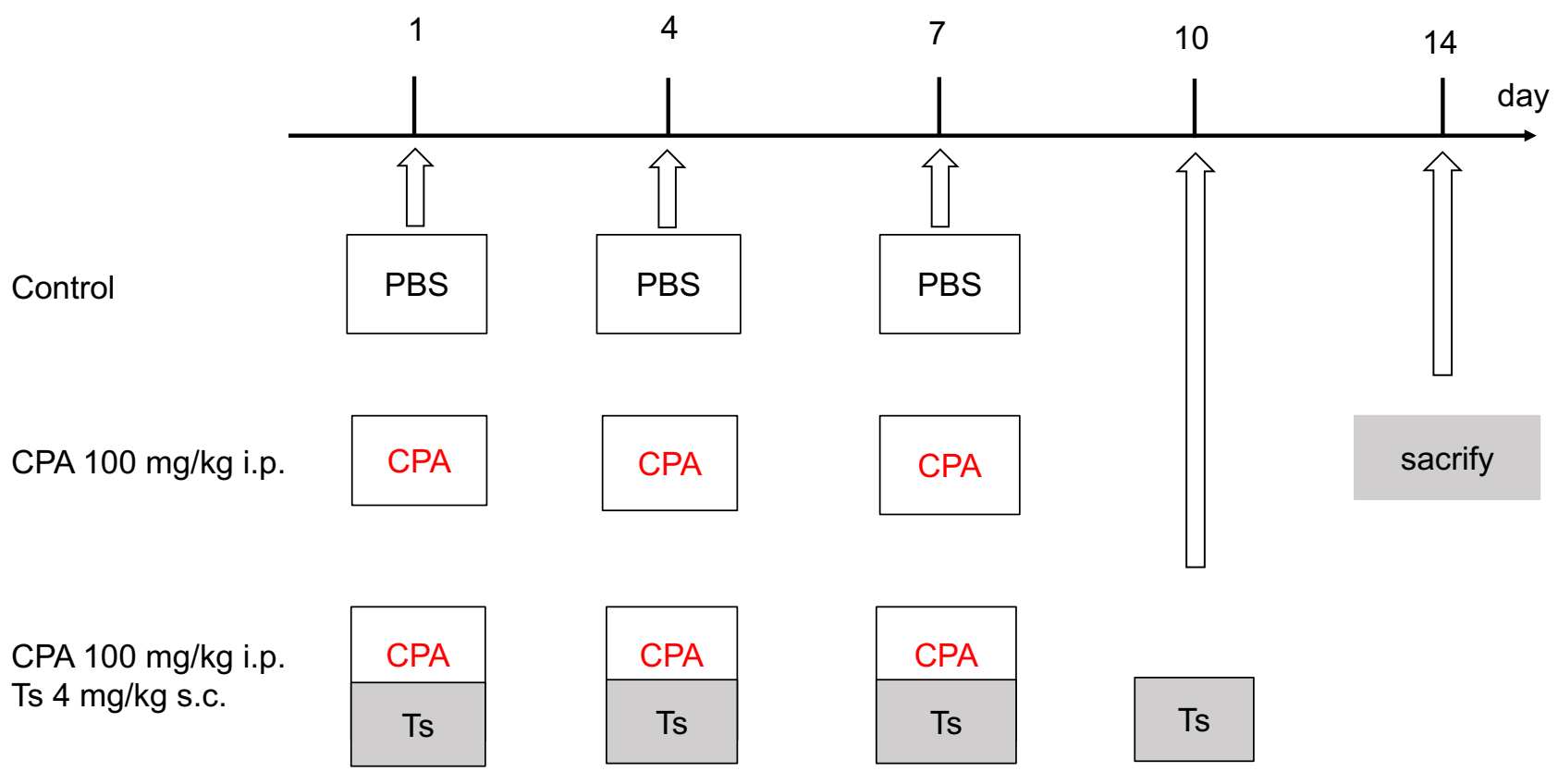

Figure I Timeline for the animal study.Notes: Cyclophosphamide ( $100 \mathrm{mg} / \mathrm{kg})$ was suspended in I\% saline, and injected into the abdominal cavity 3 times on days I, 4 and 7. Testosterone ( $4 \mathrm{mg} / \mathrm{kg}$ ) was suspended in corn oil, and subcutaneously injected 4 times (days I, 4, 7 and I0). PBS (I mL) was injected into the abdominal cavity 3 times (days I, 4 and 7) in the vehicle group. All animals were sacrificed on day 14.

Abbreviations: PBS, phosphate-buffered saline; CPA, cyclophosphamide; Ts, testosterone; i.p., intraperitoneal; s.c., subcutaneous.

making multiple comparisons in datasets with continuous variables containing more than two groups, Tukey's honestly significant difference test was used. Statistical significance was defined as $\mathrm{p}<0.05$.

\section{Results}

\section{Testosterone Inhibits}

\section{Cyclophosphamide-Induced Apoptosis in COV434 Granulosa Cells}

An MTS assay was performed using various concentrations of cyclophosphamide $(0,1,10,100,1000 \mu \mathrm{M})$ and testosterone $(0,10,100 \mathrm{nM})$ with or without $10 \mu \mathrm{M}$ flutamide (a testosterone inhibitor) in order to evaluate the effect of testosterone on the proliferation of granulosa cells treated with cyclophosphamide. The cell viability was decreased at higher concentrations of cyclophosphamide; however, it improved after treatment with testosterone. Furthermore, the improvement disappeared when flutamide was added; we found that COV434 cell growth was suppressed by cyclophosphamide in a concentrationdependent manner, and that testosterone protected against this effect (Figure 2A).

Next, to assess whether the protection of cellular proliferation by testosterone prevented the apoptosis caused by cyclophosphamide, an activated caspase-3 in situ detection assay was performed using $100 \mu \mathrm{M}$ cyclophosphamidetreated COV434 cells with vehicle (phosphate-buffered saline), $10 \mathrm{nM}$ testosterone, $100 \mathrm{nM}$ testosterone and $100 \mathrm{nM}$ testosterone plus flutamide. As shown in Figure $2 \mathrm{~B}$ and $\mathrm{C}$, the percentage of apoptotic cells was $52 \%, 17 \%, 4 \%$ and $41 \%$ in the vehicle-treated, $10 \mathrm{nM}$ testosterone-treated, $100 \mathrm{nM}$ testosterone-treated and $100 \mathrm{nM}$ testosterone plus flutamidetreated cells, respectively. The $\mathrm{p}$ values compared to vehicle were 0.005 in $10 \mathrm{nM}$ testosterone-treated cells, 0.003 in $10 \mathrm{nM}$ testosterone-treated cells and 0.7 in $100 \mathrm{nM}$ testosterone plus flutamide-treated cells; the cyclophosphamide-treated cells with testosterone showed significantly less apoptosis than the vehicle- and flutamide-treated cells. Figure 2D shows the expression of apoptotic proteins on Western blotting. The expression of BimEL and cleaved caspase- 3 in $100 \mu \mathrm{M}$ cyclophosphamide-treated cells was inhibited by $100 \mathrm{nM}$ testosterone and was not inhibited by $100 \mathrm{nM}$ testosterone with flutamide.

\section{The Effects of Testosterone in Mice Treated with Cyclophosphamide}

We evaluated the effects of testosterone on ovaries of mice treated with cyclophosphamide (Figure 3A). Five 
A

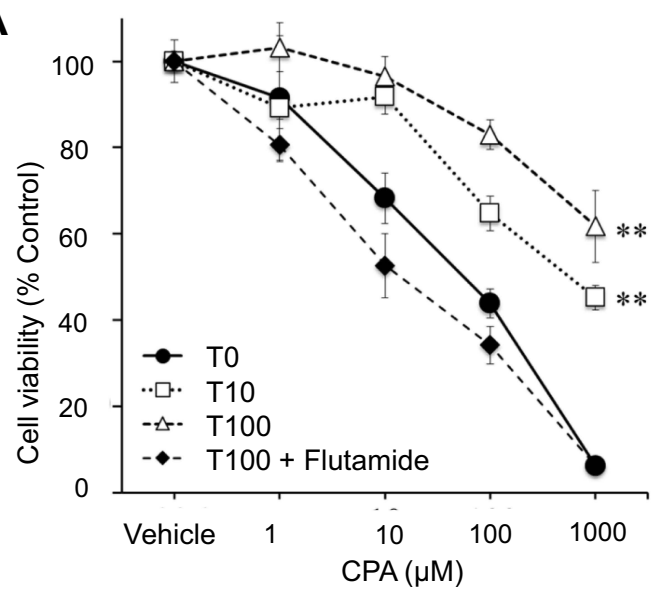

C

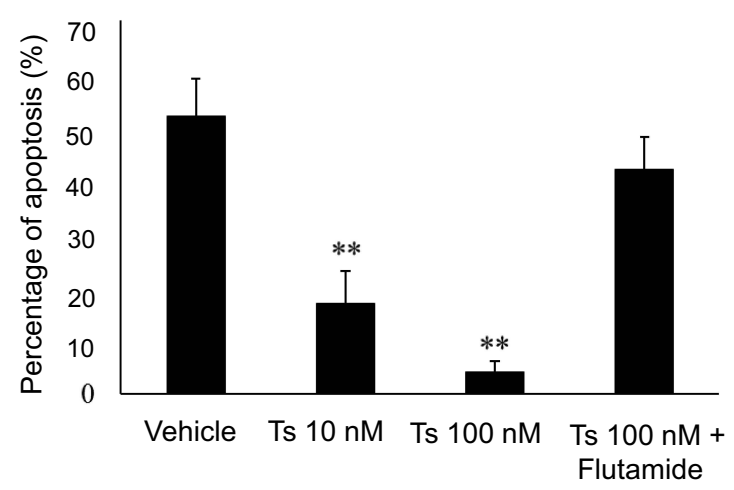

B

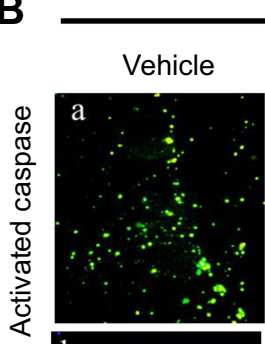

Cyclophosphamide $100 \mu \mathrm{M}$
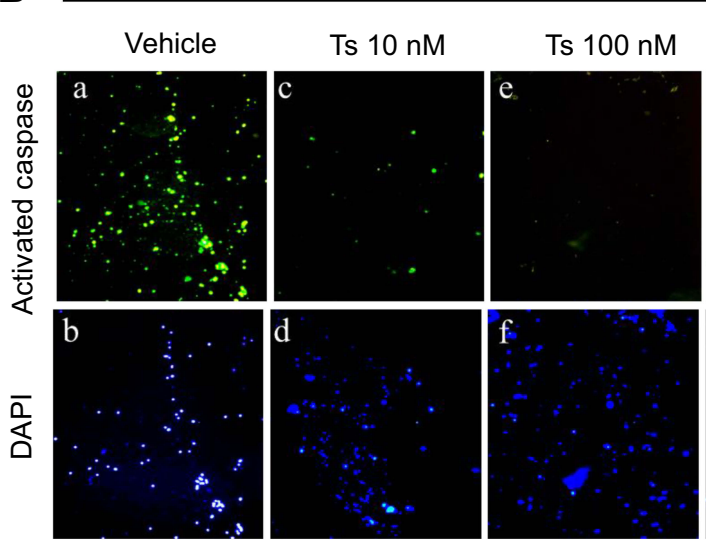

Ts $100 \mathrm{nM}+$ Flutamide

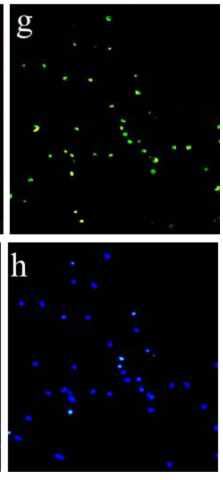

D

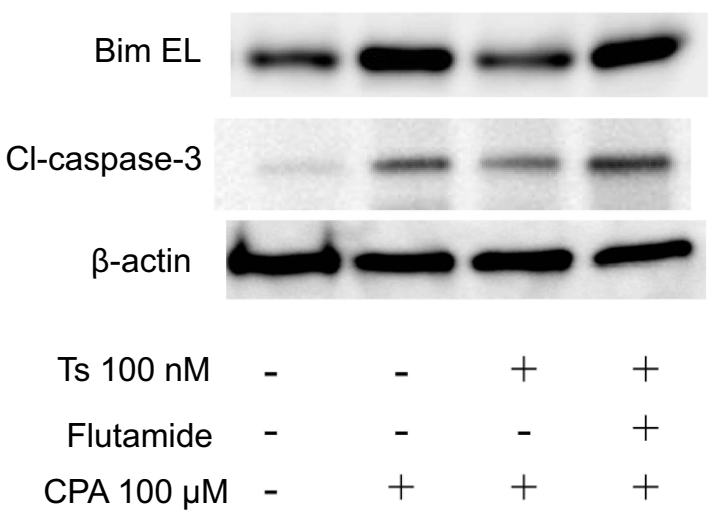

Figure 2 Testosterone inhibits cyclophosphamide-induced apoptosis in COV434 granulosa cells. Notes: (A) The granulosa cells COV434 were treated with various concentrations of cyclophosphamide (CPA; $0,1,10,100,1000 \mu \mathrm{M})$ and testosterone $(\mathrm{T} ; 0,10,100 \mathrm{nM})$ with or without testosterone inhibitor flutamide for 48 hours and then their proliferation was measured by an MTS assay. The cell viability was decreased at higher concentrations of cyclophosphamide; however, it improved after treatment with testosterone. Furthermore, the improvement disappeared when flutamide was added. (B, C) The granulosa cells were treated with $100 \mu M$ cyclophosphamide with testosterone (Ts; $0,10,100 \mathrm{nM}$ ) with or without flutamide for 48 hours and apoptotic cells were assessed by a caspase-3 activity assay. (B) Representative examples of immunostaining are shown on the left. FITC-labeled cells indicate the presence of apoptosis, and DAPI was used for counterstaining. (C) The percentage of apoptotic cells was counted using a FACScan device. Significant differences are indicated by asterisks. **p $<0.01$. (D) The expression of apoptotic proteins on Western blotting. The expression of BimEL and cleaved caspase- 3 in $100 \mu \mathrm{M}$ cyclophosphamide-treated cells was inhibited by $100 \mathrm{nM}$ testosterone and was not inhibited by $100 \mathrm{nM}$ testosterone with flutamide. Abbreviations: CPA, cyclophosphamide; T0, no testosterone; TI0, testosterone $10 \mathrm{nM}$; TI00, testosterone $100 \mathrm{nM}$; Ts, testosterone; Cl-caspase-3, Cleaved caspase-3; $\beta$ actin, beta-actin.

mice were used in each group, including phosphatebuffered saline, cyclophosphamide and cyclophosphamide plus testosterone; a total of 15 mice were used. As shown in Figure 3B, the number of primordial follicles was 38, 24 and 42 in the phosphate-buffered saline, cyclophosphamide and cyclophosphamide plus testosterone groups, respectively. The number of primordial follicles in the intra-abdominal cyclophosphamide group was significantly lower than that in the groups that received subcutaneous testosterone $(\mathrm{p}=0.03)$ or intra-abdominal phosphate-buffered saline $(\mathrm{p}=0.04)$. No significant difference was found between the phosphate-buffered saline group and the cyclophosphamide plus testosterone group. The number of primary follicles was 32, 18 and 21 in the phosphate-buffered saline, cyclophosphamide and cyclophosphamide plus testosterone groups, respectively. There were no significant differences in the number of secondary follicles between the phosphate-buffered saline and cyclophosphamide groups $(\mathrm{p}=0.3)$, cyclophosphamide and cyclophosphamide plus testosterone groups $(\mathrm{p}=0.2)$ or phosphate-buffered saline and cyclophosphamide plus testosterone groups $(\mathrm{p}=0.5)$. The number of secondary follicles was 48,58 and 42 in the phosphatebuffered saline, cyclophosphamide and cyclophosphamide plus testosterone groups, respectively. There were no significant differences in the number of secondary 
A

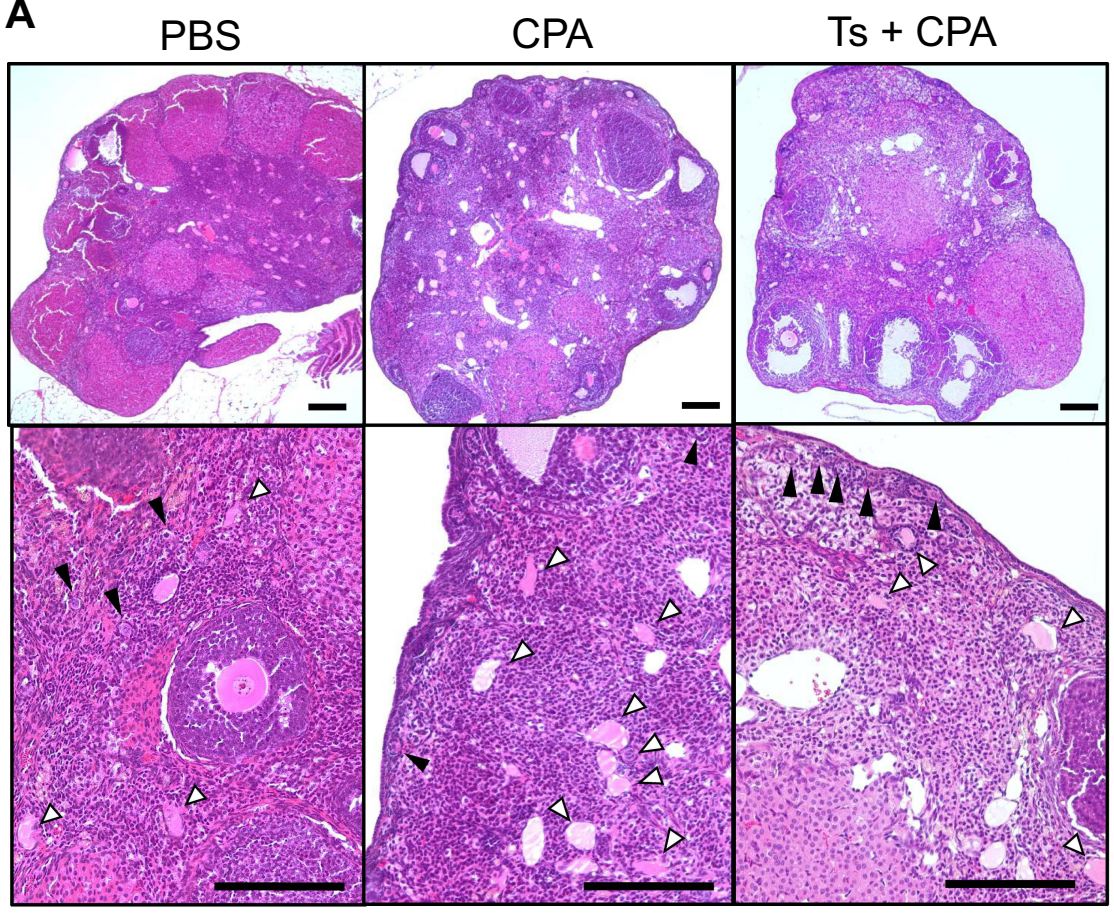

B

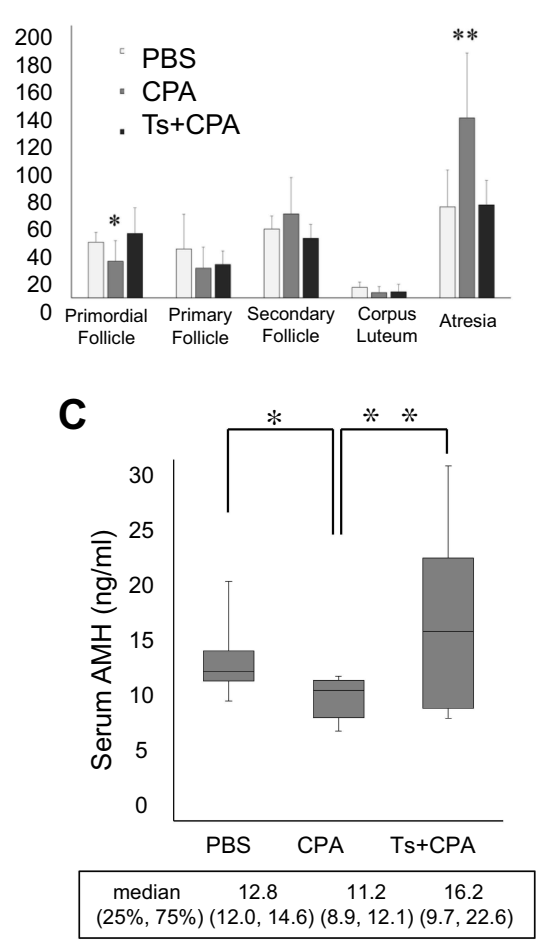

Figure 3 The effect of testosterone in mice treated with cyclophosphamide.Notes: (A) H\&E staining of the ovary of mice treated with phosphate-buffered saline (PBS), cyclophosphamide (CPA) and cyclophosphamide plus testosterone (Ts). There are abundant primordial follicles (black arrows) and a few atresia (white arrows) in the ovaries of PBS-treated mice. In contrast, there are many atresia (white arrows) in the ovaries of CPA-treated mice. A small number of primordial follicles (black arrows) were found. In the ovaries of CPA plus Ts-treated mice, abundant primordial follicles (black arrows) and a few atresia (white arrows) were found. Bar $=100 \mu \mathrm{m}$. (B) The numbers of follicles categorized into five conditions (primordial follicles, primary follicles, secondary follicles, corpus lutea and atretic follicles) were counted. The number of atretic follicles in the cyclophosphamide group was significantly higher than that in the cyclophosphamide plus testosterone and phosphate-buffered saline groups. The number of primordial follicles in the cyclophosphamide group was significantly lower than that in the cyclophosphamide plus testosterone and phosphate-buffered saline groups. (C) The serum anti-Mullerian hormone (AMH) level in the cyclophosphamide group was significantly lower than that in the cyclophosphamide plus testosterone and phosphate-buffered saline groups. Significant differences are indicated by asterisks. ${ }^{*} p<0.05$, **p $<0.01$.

Abbreviations: PBS, phosphate-buffered saline; CPA, cyclophosphamide; Ts, testosterone; AMH, anti-Mullerian hormone.

follicles between the phosphate-buffered saline and cyclophosphamide groups $(\mathrm{p}=0.3)$, cyclophosphamide and cyclophosphamide plus testosterone groups $(\mathrm{p}=0.2)$ or phosphate-buffered saline and cyclophosphamide plus testosterone groups $(\mathrm{p}=0.5)$, The number of corpus lutea was 8,3 and 4 in the phosphate-buffered saline, cyclophosphamide and cyclophosphamide plus testosterone groups, respectively. There were no significant differences in the number of corpus lutea between the phosphate-buffered saline and cyclophosphamide groups $(\mathrm{p}=0.07)$, cyclophosphamide and cyclophosphamide plus testosterone groups $(\mathrm{p}=0.24)$ or phosphate-buffered saline and cyclophosphamide plus testosterone groups $(\mathrm{p}=0.09$ ). The number of atretic follicles was 61, 135 and 66 in the phosphate-buffered saline, cyclophosphamide and cyclophosphamide plus testosterone groups, respectively. The results showed that the number of atretic follicles in the intra-abdominal cyclophosphamide group was significantly higher than that in the groups that received subcutaneous testosterone $(\mathrm{p}=0.004)$ or intra-abdominal phosphate-buffered saline $(\mathrm{p}=0.004)$. There was no significant difference between the phosphate-buffered saline and cyclophosphamide plus testosterone group $(\mathrm{p}=0.8)$. As shown in Figure 3C, the serum anti-Mullerian hormone level in the cyclophosphamide group was significantly lower than that in the cyclophosphamide with testosterone group (11.2 [8.9-12.1] vs 16.2 [9.7-22.6] $\mathrm{ng} / \mathrm{mL}, \mathrm{p}=0.003$ ) and phosphate-buffered saline group (11.2 [8.9-12.1] vs 12.8 [9.7-22.6] $\mathrm{ng} / \mathrm{mL}, \mathrm{p}=0.03$ ). Figure 4A shows the immunohistochemical analysis of cleaved Caspase-3 in the mouse ovary. The ratio of cleaved Caspase-3 positive follicles to all follicles in the cyclophosphamide group was significantly higher than that in the cyclophosphamide plus testosterone $(48.6 \%$ vs $28.4 \%, \quad \mathrm{p}=0.003)$ and phosphate-buffered saline ( $48.6 \%$ vs. $20.3 \%, \mathrm{p}=0.002$ ) groups (Figure $3 \mathrm{~B}$ ). 
A
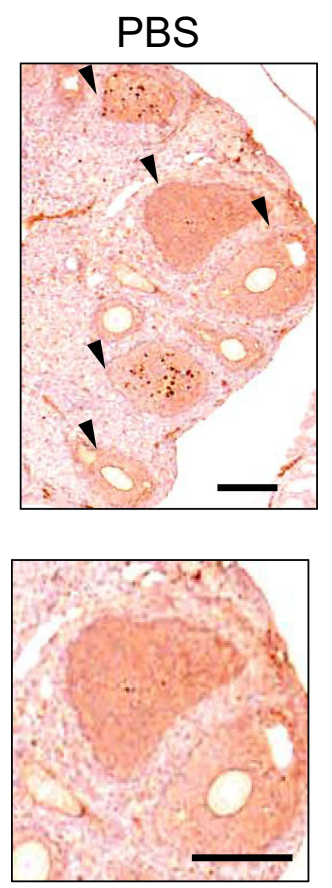
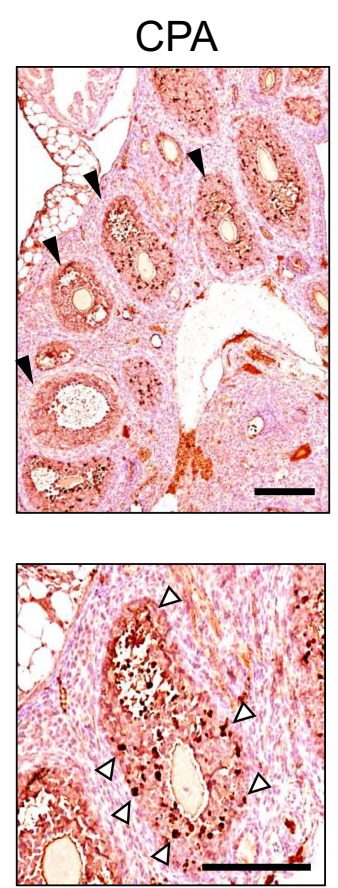

Ts + CPA
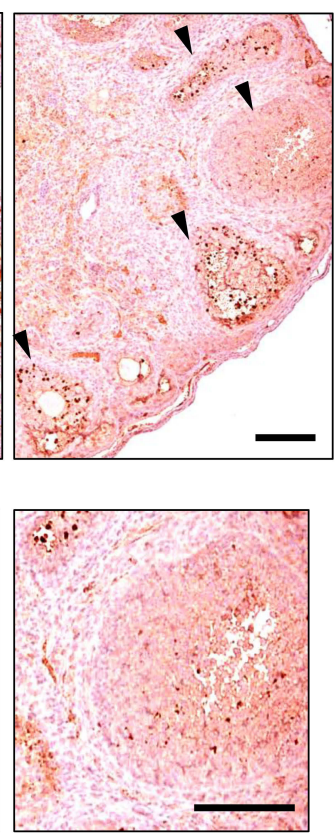

B

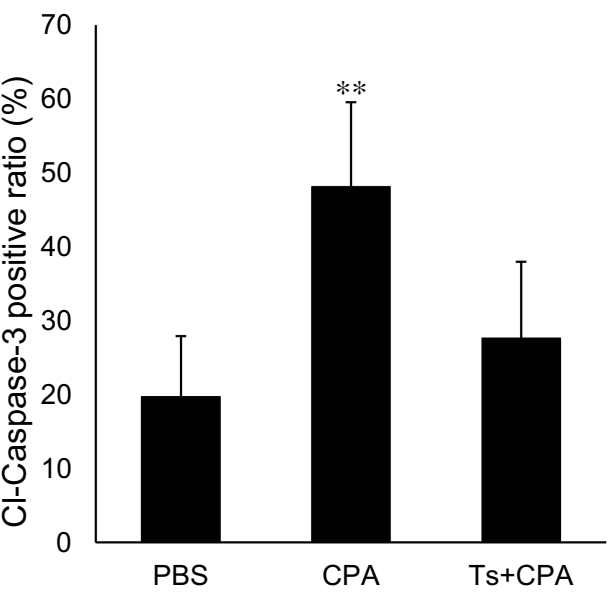

Figure 4 The immunohistochemical analysis of cleaved Caspase-3 in mouse ovary.Notes: (A) The expression of cleaved-caspase-3 (Cl-Caspase-3) on immunohistochemistry. There are many follicles in mouse ovaries (black arrows). A large number of Cleave caspase-3-positive cells (white arrows) were found in the follicles of cyclophosphamide (CPA)-treated mice. In contrast, there were fewer Cl-Caspase-3 positive cells in the follicles in phosphate-buffered saline (PBS)-treated mice and cyclophosphamide plus testosterone (Ts)-treated mice. Bar $=100 \mu \mathrm{m}$. (B) The ratio of Cl-caspase-3 positive cells in the cyclophosphamide (CPA) group was significantly higher than that in the cyclophosphamide plus testosterone (Ts) and phosphate-buffered saline (PBS) groups. ${ }^{* *} \mathrm{p}<0.0 \mathrm{I}$.

Abbreviations: CPA, cyclophosphamide; Ts, testosterone; PBS, phosphate-buffered saline; Cl-caspase-3, Cleaved caspase-3.

\section{Discussion}

In the present study, the administration of testosterone had the potential to prevent the ovarian damage induced by cyclophosphamide via the protection of granulosa cells from cyclophosphamide-induced apoptosis.

Gonadotropin-releasing hormone analogues have been administered to prevent chemotherapy-related amenorrhea in patients of reproductive age who are undergoing chemotherapy. Gonadotropin-releasing hormone analogues reduce luteinizing hormone and follicle-stimulating hormone, and thereby inhibit the proliferation of granulosa cells and the growth of follicles. Gonadotropin-releasing hormone analogue treatment maintains premature follicles in the ovary. Blumenfeld reported that gonadotropinreleasing hormone analogue treatment prevented premature ovarian failure in young patients with malignant lymphoma who receive chemotherapy. ${ }^{24}$

In previous reports, testosterone was shown to enhance follicular recruitment, ${ }^{11}$ promote follicular growth and development, ${ }^{12}$ increase the insulin-like growth factor 1 expression in the primate ovary and thus play an essential role in regulating follicular development, ${ }^{13}$ and increase follicular sensitivity to follicle-stimulating hormone stimulation via androgen receptor; ${ }^{14,15}$ testosterone is thus essential for normal follicular development. However, high concentrations of testosterone inhibit follicle development through the regulation of follicle-stimulating hormone signaling pathway. ${ }^{16}$ Follicle growth in the presence of high testosterone concentrations was promoted at the early stage but inhibited at later stages in vitro culture. In cultured granulosa cells, high testosterone concentrations induced cell proliferation. ${ }^{25}$ Similar to the effects of gonadotropin-releasing hormone, high concentrations of testosterone induced follicle development arrest and maintained premature follicles in the ovary. We previously reported that the high expression of the proapoptotic Bcl-2 member BimEL in the follicle was associated with a low serum testosterone level in patients with endometriosis. In vitro, testosterone inhibits apoptosis induced by sex steroid depletion via the PIK3/Akt-FOXO3a pathway in the granulosa cell line. ${ }^{26}$

In a randomized control trial of transdermal testosterone for patients with surgical menopause, no apparent side effects except for hypertrichosis were found. The duration of transdermal testosterone therapy was 24 weeks in the present 
study. Androgen therapy should therefore be evaluated until 24 weeks. Furthermore, given the lack of evidence concerning the efficacy and safety of androgen therapy for more than 24 weeks, androgen therapy should not be continued when patients show no apparent efficacy at 24 weeks. ${ }^{27}$ Congenital malformations may develop when testosterone is used in women of reproductive age, as in mammals, ${ }^{28}$ including humans, ${ }^{29}$ sexes are distinguished by the exposed concentration of testosterone during the prenatal period.

Anti-Mullerian hormone is produced by granulosa cells associated with the primordial to antral follicle; the serum anti-Mullerian hormone level is reflected in the number of follicles. $^{30-32}$ The present findings showed that testosteronetreated cyclophosphamide-induced mice had higher serum anti-Mullerian hormone levels than cyclophosphamideinduced mice. These findings suggest that treatment with testosterone prevents the reduction of follicles caused by cyclophosphamide.

The present study was associated with three major limitations that may reduce its value. First, the appropriate concentration of testosterone has not been confirmed. Second, other anticancer agents aside from cyclophosphamide were not evaluated. Thirds, no clinical data or materials were used. As such, our results must be confirmed in further investigations.

\section{Conclusion}

Testosterone has the potential to prevent cyclophosphamide-induced ovary damage by protecting granulosa cells from cyclophosphamide-induced apoptosis.

\section{Author Contributions}

All authors contributed to the data analysis, drafting and revising the article, gave their final approval of the version to be published, and agreed to be accountable for all aspects of the work.

\section{Funding}

This work was supported by a JSPS KAKENHI Grant, Number 17K11304 (to M.O.).

\section{Disclosure}

The authors report no conflicts of interest in this work.

\section{References}

1. Barton SE, Najita JS, Ginsburg ES, et al. Infertility, infertility treatment, and achievement of pregnancy in female survivors of childhood cancer: a report from the Childhood Cancer Survivor Study cohort. Lancet Oncol. 2013;14(9):873-881. doi:10.1016/S1470-2045(13)70251-1
2. Green DM, Kawashima T, Stovall M, et al. Fertility of female survivors of childhood cancer: a report from the childhood cancer survivor study. J Clin Oncol. 2009;27(16):2677-2685. doi:10.1200/ JCO.2008.20.1541

3. Del Mastro L, Ceppi M, Poggio F, et al. Gonadotropin-releasing hormone analogues for the prevention of chemotherapy-induced premature ovarian failure in cancer women: systematic review and meta-analysis of randomized trials. Cancer Treat Rev. 2014;40 (5):675-683. doi:10.1016/j.ctrv.2013.12.001

4. Castelo-Branco C, Nomdedeu B, Camus A, Mercadal S, Martinez de Osaba MJ, Balasch J. Use of gonadotropin-releasing hormone agonists in patients with Hodgkin's disease for preservation of ovarian function and reduction of gonadotoxicity related to chemotherapy. Fertil Steril. 2007;87(3):702-705. doi:10.1016/j.fertnstert.2006. 10.004

5. Loren AW, Mangu PB, Beck LN, et al. Fertility preservation for patients with cancer: American Society of Clinical Oncology clinical practice guideline update. J Clin Oncol. 2013;31(19):2500-2510. doi:10.1200/JCO.2013.49.2678

6. Chow EJ, Stratton KL, Leisenring WM, et al. Pregnancy after chemotherapy in male and female survivors of childhood cancer treated between 1970 and 1999: a report from the Childhood Cancer Survivor Study cohort. Lancet Oncol. 2016;17(5):567-576. doi:10.10 16/S1470-2045(16)00086-3

7. Sonigo C, Beau I, Grynberg M, Binart N. AMH prevents primordial ovarian follicle loss and fertility alteration in cyclophosphamide-treated mice. FASEB J. 2019;33(1):1278-1287. doi:10.1096/fj.201801089R

8. Jamil Z, Perveen K, Malik R, Avesi L. Predictive accuracy of anti mullerian hormone as indicator of ovarian follicle loss in cyclophosphamide treated mice. J Pak Med Assoc. 2017;67(10):1470-1475.

9. Kalich-Philosoph L, Roness H, Carmely A, et al. Cyclophosphamide triggers follicle activation and "burnout"; AS101 prevents follicle loss and preserves fertility. Sci Transl Med. 2013;5(185):185ra162. doi:10.1126/scitranslmed.3005402

10. Chen XY, Xia HX, Guan HY, Li B, Zhang W. Follicle loss and apoptosis in cyclophosphamide-treated mice: what's the matter? Int J Mol Sci. 2016;17(6).

11. Steckler T, Wang J, Bartol FF, Roy SK, Padmanabhan V. Fetal programming: prenatal testosterone treatment causes intrauterine growth retardation, reduces ovarian reserve and increases ovarian follicular recruitment. Endocrinology. 2005;146(7):3185-3193. doi:10.1210/ en.2004-1444

12. Vendola K, Zhou J, Wang J, Famuyiwa OA, Bievre M, Bondy CA. Androgens promote oocyte insulin-like growth factor I expression and initiation of follicle development in the primate ovary. Biol Reprod. 1999;61(2):353-357. doi:10.1095/biolreprod61.2.353

13. Vendola K, Zhou J, Wang J, Bondy CA. Androgens promote insulin-like growth factor-I and insulin-like growth factor-I receptor gene expression in the primate ovary. Hum Reprod. 1999;14(9):2328-2332. doi:10.1093/ humrep/14.9.2328

14. Cardenas H, Herrick JR, Pope WF. Increased ovulation rate in gilts treated with dihydrotestosterone. Reproduction. 2002;123(4):527-533. doi:10.1530/rep.0.1230527

15. Nielsen ME, Rasmussen IA, Kristensen SG, et al. In human granulosa cells from small antral follicles, androgen receptor mRNA and androgen levels in follicular fluid correlate with FSH receptor mRNA. Mol Hum Reprod. 2011;17(1):63-70. doi:10.1093/molehr/gaq073

16. Caldwell AS, Middleton LJ, Jimenez M, et al. Characterization of reproductive, metabolic, and endocrine features of polycystic ovary syndrome in female hyperandrogenic mouse models. Endocrinology. 2014;155(8):3146-3159. doi:10.1210/en.2014-1196

17. Laird M, Thomson K, Fenwick M, Mora J, Franks S, Hardy K. Androgen stimulates growth of mouse preantral follicles in vitro: interaction with follicle-stimulating hormone and with growth factors of the TGFbeta superfamily. Endocrinology. 2017;158(4):920-935. doi:10.1210/en.2016-1538 
18. Peng KW, Myers R, Greenslade A, et al. Using clinically approved cyclophosphamide regimens to control the humoral immune response to oncolytic viruses. Gene Ther. 2013;20(3):255-261. doi:10.1038/ gt.2012.31

19. Browne HN, Moon KS, Mumford SL, et al. Is anti-Mullerian hormone a marker of acute cyclophosphamide-induced ovarian follicular destruction in mice pretreated with cetrorelix? Fertil Steril. 2011;96 (1):180-186.e182. doi:10.1016/j.fertnstert.2011.04.008

20. Meirow D, Lewis H, Nugent D, Epstein M. Subclinical depletion of primordial follicular reserve in mice treated with cyclophosphamide: clinical importance and proposed accurate investigative tool. Hum Reprod. 1999;14(7):1903-1907. doi:10.1093/humrep/14.7.1903

21. Sun M, Wang S, Li Y, et al. Adipose-derived stem cells improved mouse ovary function after chemotherapy-induced ovary failure. Stem Cell Res Ther. 2013;4(4):80. doi:10.1186/scrt231

22. Meirow D, Epstein M, Lewis H, Nugent D, Gosden RG. Administration of cyclophosphamide at different stages of follicular maturation in mice: effects on reproductive performance and fetal malformations. Hum Reprod. 2001;16(4):632-637. doi:10.1093/humrep/16.4.632

23. Weil S, Vendola K, Zhou J, Bondy CA. Androgen and follicle-stimulating hormone interactions in primate ovarian follicle development. J Clin Endocrinol Metab. 1999;84(8):2951-2956. doi:10.1210/jcem.84.8.5929

24. Blumenfeld Z, Avivi I, Linn S, Epelbaum R, Ben-Shahar M, Haim N. Prevention of irreversible chemotherapy-induced ovarian damage in young women with lymphoma by a gonadotrophin-releasing hormone agonist in parallel to chemotherapy. Hum Reprod. 1996;11 (8):1620-1626. doi:10.1093/oxfordjournals.humrep.a019457
25. Liu T, Cui YQ, Zhao H, et al. High levels of testosterone inhibit ovarian follicle development by repressing the FSH signaling pathway. J Huazhong Univ Sci Technolog Med Sci. 2015;35 (5):723-729. doi:10.1007/s11596-015-1497-Z

26. Ono YJ, Tanabe A, Nakamura Y, et al. A low-testosterone state associated with endometrioma leads to the apoptosis of granulosa cells. PLoS One. 2014;9(12):e115618. doi:10.1371/journal.pone.0115618

27. Davis SR, Moreau M, Kroll R, et al. Testosterone for low libido in postmenopausal women not taking estrogen. $N$ Engl J Med. 2008;359 (19):2005-2017. doi:10.1056/NEJMoa0707302

28. Vom Saal FS, Bronson FH. Sexual characteristics of adult female mice are correlated with their blood testosterone levels during prenatal development. Science (New York, NY). 1980;208(4444):597-599. doi:10.1126/science. 7367881

29. McNairn AJ, Chuang CH, Bloom JC, Wallace MD, Schimenti JC. Female-biased embryonic death from inflammation induced by genomic instability. Nature. 2019;567(7746):105-108. doi:10.1038/ s41586-019-0936-6

30. Durlinger AL, Gruijters MJ, Kramer P, et al. Anti-Mullerian hormone inhibits initiation of primordial follicle growth in the mouse ovary. Endocrinology. 2002;143(3):1076-1084. doi:10.1210/endo.143.3.8691

31. Durlinger AL, Kramer P, Karels B, et al. Control of primordial follicle recruitment by anti-Mullerian hormone in the mouse ovary. Endocrinology. 1999;140(12):5789-5796. doi:10.1210/endo.140.12.7204

32. Broer SL, Broekmans FJ, Laven JS, Fauser BC. Anti-Mullerian hormone: ovarian reserve testing and its potential clinical implications. Hum Reprod Update. 2014;20(5):688-701. doi:10.1093/humupd/dmu020

\section{Publish your work in this journal}

OncoTargets and Therapy is an international, peer-reviewed, open access journal focusing on the pathological basis of all cancers, potential targets for therapy and treatment protocols employed to improve the management of cancer patients. The journal also focuses on the impact of management programs and new therapeutic agents and protocols on patient perspectives such as quality of life, adherence and satisfaction. The manuscript management system is completely online and includes a very quick and fair peer-review system, which is all easy to use. Visit http://www.dovepress.com/ testimonials.php to read real quotes from published authors. 